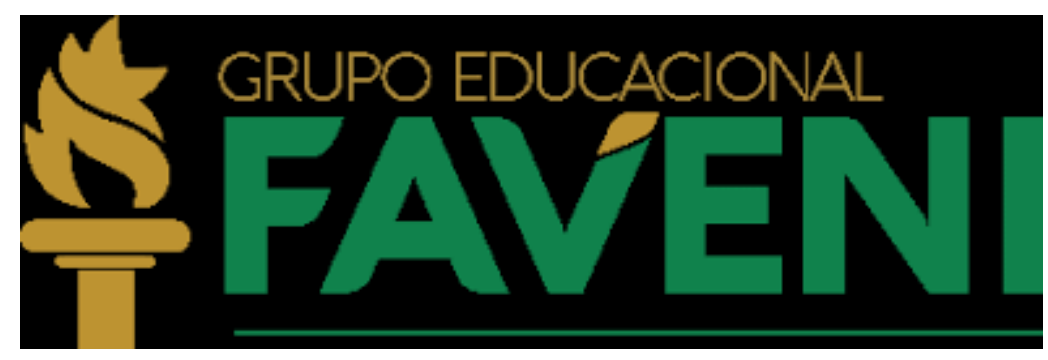

FACULDADE VENDA NOVA DO IMIGRANTE

METTODOLOGIA DO ENSINO DE FILOSOFIA E SOCIOLOGIA

VERA LUCIA CASARIN

A IMPORTÂNCIA DA FILOSOFIA E SOCIOLOGIA NO ENSINO MÉDIO

LUÍS EDUARDO MAGALHÃES - BA

28 DE NOVEMBRO DE 2019 


\title{
A IMPORTÂNCIA DA FILOSOFIA E SOCIOLOGIA NO ENSINO MÉDIO
}

\author{
Vera Lucia Casarin ${ }^{1}$
}

\begin{abstract}
RESUMO: O presente texto busca esclarecer a importância da filosofia e sociologia no Ensino Médio, duas disciplinas essenciais para o desenvolvimento da cidadania. Foram às áreas que deram e ainda dão retorno voltado para o lado social diante a sociedade. É respeitável abrir ambiente para entender os conhecimentos filosóficos e sociológicos como saberes construtivos e constitutivos para o desenvolvimento de um dos fundamentais papéis sociais dentro do ambiente escolar. A escola é um ambiente favorável para a ampliação de maneiras pautadas ao pensamento, onde o aluno deve se situar dentro do ambiente em que vive, colaborar para a constituição de uma sociedade justa e participativa. Um dos alicerces da escola é a educação para o aprendizado da cidadania, desta forma se faz necessário compreender que essas disciplinas são fundamentais para a constituição do conhecimento e aforismo para além dos muros escolares. Esse trabalho centraliza seu foco na importância das disciplinas filosofia e sociologia dentro do currículo do ensino médio. Escola lugar em que as duas disciplinas colaboram para um ambiente tolerante, humano, onde o adolescente é capaz de tomar decisões com criticidade, atuando como transformador da sociedade.
\end{abstract}

PALAVRAS-CHAVE: Filosofia. Sociologia. Educação. Cidadania.

\section{INTRODUÇÃO}

Levar o conhecimento as futuras gerações é uma ação comum do ser humano e a escola é um dos primeiros ambientes fora do meio familiar de socialização. A partir do primeiro contato na Educação Infantil até atingir o Ensino Médio o estudante precisa percorrer um caminho que o conduzirá além do conhecimento, vão agregar no seu percurso valores e convenções culturais.

A escola enquanto instituição de ensino fica responsável por mediar saberes diversificados considerados imprescindíveis para o desenvolvimento pleno da pessoa. O ambiente escolar se torna também responsável no que se refere a ampliar maneiras pautadas ao aforismo, então aqui entra a legislação 
educacional, e da inclusão da Filosofia e Sociologia no currículo do ensino médio.

Hoje as disciplinas de Filosofia e Sociologia são alicerces no que tange o preparativo dos adolescentes para cumprir a cidadania, cidadania que ainda alimenta expectativas de um mundo melhor. Discutir o contexto se faz imprescindível perante a realidade que ainda se encontra, pois essas disciplinas ainda são questionadas diante sociedade, pois envolve responsabilidade na formação do aluno como um indivíduo, capaz de encontrar o seu lugar no espaço e tempo, encarar todas os problemas como cidadão responsável e consciente do mundo que habita.

Essas duas disciplinas possuem um papel primordial no alargamento do procedimento do aluno como cidadão, pois é através delas que também se formam os primeiros críticos e pensantes. Assim é importante o entendimento e conscientização de que o professor mediador tem que assumir a responsabilidades tendo em mente a necessidade do questionamento.

A escolha do tema foi significativa, pois, falar sobre a importância da filosofia e sociologia no ensino médio é entrar em um campo abstruso, pois ainda se nota a dificuldade da sociedade distinguir que essas duas disciplinas chegaram para contribuir com os alunos, demonstrando que eles são o futuro do país e não meramente um elemento de educação que se encontra dentro da escola.

O objetivo principal do trabalho é provar o valor da Filosofia e Sociologia para o Ensino Médio, analisando as formas como essas disciplinas afetam os alunos, fazendo-os distinguir a sua função admirável dentro e fora do ambiente escolar.

Com este trabalho se espera auxiliar os professores que trabalham com a aprendizagem e que acreditam que na escola como espaço para se desenvolver a reflexão sobre o aluno como um todo, auxiliando na contribuição do desenvolvimento de uma consciência critica e transformadora.

O ambiente escolar e um dos locais externos para se formar elo forte e importante compartilhando responsabilidades para garantir a educação de qualidade. O método seguido na formulação deste trabalho foi baseada em pesquisas bibliográficas, visando aprofundar o tema para melhor entrosamento do assunto a seriedade da filosofia ensino médio. Para ом\} melhor compreensão 
do tema esse trabalho será dividido em tópicos sendo o primeiro: A importante relação Filosofia e Sociologia e o aluno, A Filosofia: uma nova forma de se pensar no mundo, A Sociologia e o crescimento do Educando em seguida conclusão e referências.

\section{A IMPORTANTE RELAÇÃO FILOSOFIA, SOCIOLOGIA E O ALUNO}

Ao longo da história as disciplinas de filosofia e sociologia entraram e saíram do currículo da educação básica. Com a LDB/96, intensificaram os debates a respeito da inclusão e necessidades dos conhecimentos filosóficos e sociológicos no ensino médio. Ainda com resistências o Parecer CNE/CEB $n^{\circ}$ $38 / 2006$ passou para segundo plano.

O Parecer do CNE/CEB n²2/2008 questiona a necessidade de aplicação de lei, vem para tratar dos possíveis conflitos da estrutura de cursos conferidas pela LDB/96 a todos os sistemas de ensino, e prazos que seja implantada a obrigatoriedade dessas disciplinas e finalmente o Parecer foi aprovado pela Resolução do CNE/CEB n 1/2009, que determina:

\footnotetext{
Art. $1^{\circ}$ Os componentes curriculares Filosofia e Sociologia são obrigatórios ao longo de todos os anos do Ensino Médio, qualquer que seja a denominação e a organização do currículo, estruturado este por sequência de séries ou não, composto por disciplinas ou por outras formas flexíveis.

Art. $2^{\circ}$ Os sistemas de ensino deverão estabelecer normas complementares e medidas concretas visando à inclusão dos componentes curriculares Filosofia e Sociologia em todas as escolas, públicas e privadas, obedecendo aos seguintes prazos de implantação: 1 - início em 2009, com a inclusão obrigatória dos componentes curriculares Filosofia e Sociologia em, pelo menos, um dos anos do Ensino Médio, preferentemente a partir do primeiro ano do curso; II - prosseguimento dessa inclusão ano a ano, até 2011, para os cursos de Ensino Médio com 3 (três) anos de duração, e até 2012, para os cursos com duração de 4 (quatro) anos." (BRASIL, 2009a)

Deste então Filosofia e Sociologia promovem reflexão durante as aulas
} são importante, pois fortalece atitudes influentes onde indivíduo assume uma postura perante a realidade, desafiando sempre em que encontrar algum problema, procurando solucioná-lo e desta forma dando inicio a novas indagações. 
São disciplinas que só agregam conhecimentos e pensamento crítico ao aluno auxiliando-os como cidadãos pensantes capazes de questionar o mundo que o cerca, além de proporcionar momentos de discussões, subsidiando temas como ética, violência, movimentos sociais, respeito às diversidades culturais, o existencialismo, temas importantes para o desenvolvimento de valores.

A educação escolar vem para ocupar lugar de destaque na vida dos indivíduos, pois ela é a responsável pela formação de cidadãos que irão impactar a sociedade através de ações coletivas ou individuais, desta forma o papel da escola vai além da mera transmissão de conhecimentos, ela é importante na formação de pensamento crítico do indivíduo, afinal segundo Gonh (1997, p.30) "a cidadania não se constrói por decretos ou intervenções externas... Ela se constrói como um processo interno, no interior da prática social em curso, com fruto do acúmulo das experiências engendradas".

Ao se pensar na construção do seu pensamento crítico durante processo de formação, sendo capazes de compreender as diversificadas formas de relações sociais, nota-se que essas duas disciplinas vieram para complementar à formação de um cidadão consciente que irá contribuir para a construção e transformação de uma sociedade mais justas, respeitando as diversidades culturais e a natureza ao seu redor. Através do pensamento crítico e do questionamento de acordo com Guimarães, os estudantes serão capazes de realizar:

\begin{abstract}
[...] o desmonte de argumentos popularmente incontestáveis; o rompimento com concepções aceitas como normais; a contrariedade em relação à expectativa de situações naturalmente esperadas até mesmo pelos jovens, a despeito de toda energia renovadora da idade. Desnaturalizar é tratar os fenômenos sociais a partir de sua historicidade; é entender que a vida em sociedade não está dada: é o resultado da atividade humana (GUIMARÃES, 2014, p. 26).
\end{abstract}

Então pode se falar que tanto a filosofia como a sociológica possuem uma função importante dentro do ambiente escolar, que vai além da disciplina, elas são o alicerce do aluno para que ele consiga desenvolver o seu potencial, sendo capaz de conseguir compreender todos os direitos e deveres necessários para conseguir viver em harmonia na sociedade. 


\title{
A FILOSOFIA: UMA NOVA FORMA DE SE PENSAR NO MUNDO
}

Ao analisar a origem histórica em primeiro lugar da filosofia, o porquê da importância dela em sala de aula, será necessário retornar a antiguidade clássica, momento em que pensadores gregos começarem a investigar e tentar compreender de forma crítica a realidade em que estavam inseridos, entre ela Tales de Mileto e Sócrates, que instituíram novas formas para que se pudesse observar e analisar o mundo.

\begin{abstract}
a primeira resposta para a pergunta 'O que é filosofia?' poderia ser : a decisão de não aceitar como naturais, óbvias e evidentes as coisas, as ideias, os fatos, as situações, os valores, os comportamentos de nossa existência cotidiana; jamais aceitá-los sem antes have-los investigado e compreendido. (CHAUÍ, 2010, p. 21).
\end{abstract}

Chauí chama a atenção para importância da filosofia na vida de qualquer indivíduo, sendo considerada fundamental em todos os momentos da vida do ser humano, pois propicia reflexões e críticas sempre voltadas para o beneficio do conhecimento para o mundo e para o homem, desta forma o aluno diante de questões desafiadoras irá refletir e procurar a melhor solução e outras indagações irá surgir.

A filosofia no Brasil é um dilema, a cada nova estruturação curricular, o governo discute sobre a continuidade ou não desta disciplina em favor da educação, com nova redação a Base Nacional Comum Curricular, reconhece o compromisso que o Estado brasileiro tem com a "promoção de uma educação integral e desenvolvimento pleno dos estudantes voltado ao acolhimento com respeito às diferenças e sem discriminação e preconceitos" (BRASIL, 2017, p. $5)$.

Considerando a Base Nacional Comum Curricular como um texto autêntico e legal perante a lei, ela vem para estabelecer um conjunto de conteúdos que levam a aprendizagem que se faz essencial para que todos os alunos consigam desenvolver ao logo dos anos, nos bancos escolares, formação integral e construção de uma nova sociedade democrática e inclusiva. Desta 
forma nota-se que a nova redação da BNCC vem para:

[...] intensificar os questionamentos sobre si próprios e sobre o mundo em que vivem, o que Ihes possibilita não apenas compreender as temáticas e conceitos utilizados, mas também problematizar categorias, objetos e processos. Desse modo, podem propor e questionar hipóteses sobre as ações dos sujeitos e, também, identificar ambiguidades e contradições presentes tanto nas condutas individuais como nos processos e estruturas sociais. (BRASIL, 2017, p. 548).

Com a nova redação que a Base Nacional Comum é possível observar que ela não cita mais a formação integral que é direito de todos os alunos, desta forma os alunos que durante o período regular de ensino tiveram por algum motivo seus direitos negados, com esta nova redação a filosofia vem para formar jovens que estão estudando na educação básica regular de ensino. Mesmo a BNCC colocando a aprendizagem como essencial, retira o direito dos demais módulos da educação como no caso a Educação de Jovens e Adultos.

A filosofia é essencial na formação do indivíduo, pois dá oportunidade para que consigam realizar de forma organizada seu pensamento e resgatar a individual. O Ensino médio é uma fase importante da educação, ela é a responsável pela formação do jovem e sua personalidade e neste momento entra a filosofia de forma colaborativa, como um alicerce para a formação da personalidade do aluno, assim afirma Kohan:

\begin{abstract}
Não considero interessante apenas que a filosofia ocupe espaços. Dentro e fora das escolas, importa, fundamentalmente, compreender o que ela faz nesses espaços, o tipo de filosofia que se pratica (e ensina), sua relação com outras áreas do saber, com a instituição escolar e as outras instituições da vida econômica, social e política do país. Convém, especificamente, considerar a relação que professores e alunos envolvidos com a filosofia estabelecem entre si e com ela. Importa, antes de mais nada, o tipo de pensamento que se afirma e se promove sob o nome de filosofia.(KOHAN, 2002, p.22).
\end{abstract}

O saber filosófico é preocupante para os governantes, pois faz com que o indivíduo enfrente a sociedade de forma critica e reflexiva, questionando as suas vontades. Não aceita o mundo como é imposto. Quer lutar por seus direitos, reconhece, analise o seu próprio pensamento, e percebe que está no mundo para fazer a diferença. Para os governantes a filosofia faz com que indivíduo, entenda o que é certo e errado, promessas que não são cumpridas, 
transformam-se em questionadores, capazes de interiorizar, criticar, e não aceitar as formas de conhecimento e discurso que lhe é imposta.

\section{A SOCIOLOGIA E O CRESCIMENTO DO EDUCANDO}

A Sociologia tem enfrentando muitos desafios para conseguir permanecer dentro do currículo escolar, ainda hoje a disciplina é motivo discussões políticas. Enquanto alguns lutam pela sua permanência, outros querem simplesmente retira-la do currículo novamente.

A disciplina demorou muitos anos para ser incluída dentro do currículo, sua obrigatoriedade só aconteceu em 02 de junho de 2008, tornando-a obrigatória nas escolas públicas e primadas de ensino médio. Essa lei veio para alterar o disposto no artigo 36 da Lei de Diretrizes e Bases da Educação Nacional, lei no 9394 de 1996, a qual em seu parágrafo $1^{\circ}$, inciso III afirmava que o ensino de sociologia e filosofia era necessário ao exercício da cidadania, sem, todavia explicitar sua obrigatoriedade como disciplina escolar. De acordo com Silva:

\footnotetext{
Na verdade a sociologia - junto com a filosofia - só tornou-se disciplina obrigatória nas três séries do ensino médio apenas em 2009. Porém, é comum encontrar diversas situações nas escolas do país. Por exemplo, em algumas a disciplina nem se chama Sociologia - às vezes, dá-se o nome de "atualidades" (SILVA, 2010, p.16).
}

Desde então a Sociologia enquanto ciência que estuda a sociedade tem a necessidade de chagar a sua prática sem deter somente teoria, mas nota-se que faltam recursos sem que possui somente uma aula durante a semana o que prejudica a realização de um trabalho de excelência ,

A Sociologia possui uma metodologia de aprendizagem diferenciada, sendo uma importante disciplina para os educandos em especial o Ensino Médio. Pois vem para colaborar com o crescimento pessoal do aluno, através do resgate da importância de um bom convívio social saudável. Garcia cita como um dos importantes objetivos da Sociologia: 
Ampliar o conhecimento sobre o ser humano e suas interações sociais. A Sociologia revela a sociedade como ela é de fato, e não como ela deveria ser. $\mathrm{O}$ propósito da Sociologia é o de contribuir para uma melhor compreensão a respeito da sociedade, o que permite que medidas cabíveis sejam tomadas para melhorar a vida daqueles que dela fazem parte. (GARCIA. 2013, p.260).

O ensino de Sociologia além de melhor compreensão do mundo, também busca a atuação do indivíduo na sociedade, se ajustando e se conscientizando como cidadão. A sociologia vem para colaborar para que a vida em sociedade seja mais tolerante com as diferenças, transformações sociais e intelectuais procurando diminuir o preconceito social, mostrando para cada indivíduo o seu papel e lugar no mundo. Segundo os Parâmetros Curriculares Nacionais para o Ensino Médio:

\begin{abstract}
O ensino de Sociologia busca uma melhor atuação do indivíduo na sociedade em que está inserido, o que não está distante dos objetivos traçados para o ensino médio que propõe preparar o indivíduo para o trabalho e para o exercício da cidadania, consolidando e aprofundando os conhecimentos, se aprimorando como pessoa humana, instigandoo a autonomia intelectual e a criticidade. (BRASIL, 2000).
\end{abstract}

Desde que a obrigatoriedade da sociologia nas escolas temas importantes para a construção do aluno são trabalhados em sala de aula, mesmo que de forma sintetizada, entre os temas encontram-se o socialismo, consumismo, trabalho, instabilidade social, alienação, temas importantes que no futuro irão colaborar com uma visão diferenciada do mundo. Candau, vem para complementar que:

Educar para a cidadania exige educar para a ação político-social e esta, para ser eficaz, não pode ser reduzida ao âmbito individual. Educar para a cidadania é educar para a democracia que dê provas de sua credibilidade de intervenção na questão social e cultural. É incorporar a preocupação ética em todas as dimensões da vida pessoal e social. (CANDAU, 1999, p.112).

A partir do conhecimento de muitos temas e conceitos, os alunos conseguirão entender as políticas públicas, a violência, religião e principalmente todos os tipos de preconceitos e o discurso governamental que vem para reprimir. 
Desta forma observa-se que a sociologia na educação é base para que se desenvolva os direitos políticos, sociais e também trabalhistas, reduzindo a desigualdade tanto sociais como educacionais e ampliando todas as oportunidades para que os alunos se transformem em cidadãos e possuam qualidade de vida perante a sociedade.

\section{CONCLUSÃO}

Liberdade, difusão de ideias, opiniões, valores e quantas outras denominações recebidas. A liberdade é alimentada pelo sonho humano é o direito que temos de ir e vir, de escolha, direito à informação, a comunicação, liberdade expressão, também conhecida como liberdade de pensamento. A escola é o ambiente em que devem ser desenvolvidas atitudes relacionadas ao pensamento, entre 0 direito de liberdade também se encontra o direito a Filosofia e Sociologia dentro do ambiente escolar.

O sistema educativo passa por processos de legitimação do saber. Agora é o momento em que os professores de filosofia e sociologia precisam romper com as dificuldades e fazer com que os alunos que estão envolvidos neste ambiente educacional saibam aproveitar o momento de tantas reformas educacionais para fortalecer a necessidade da continuidade destas disciplinas no currículo.

Apresentando o motivo real por que está inserido no currículo, o lado colaborativo com a sociedade e seus estudos, facilitando a inserção do indivíduo no meio social, pois abrangem vários aspectos da vida do aluno, traz discussões pertinentes e temáticas do dia-a-dia. Sendo uma forma atualizada de aprendizagem, resgatando a ideia de sociedade, fazendo com que alunos reflitam conceitos filosóficos e sociológicos importantes sobre a vida em sociedade.

Assim é possível compreender que a base curricular precisa ser fortalecida, e entender que a filosofia e sociologia são disciplinas abrangentes e que colabora com outras disciplinas, principalmente na compreensão e leitura de mundo, desenvolvendo e favorecendo o desenvolvimento do cidadão.

Desta forma o papel fundamental da filosofia e sociologia é levar o aluno a se envolver em questionamentos, denúncia, reflexão crítica, tendo como base 
contextos históricos, sociais e políticos, evidenciando que o aluno possui papel fundamental no mundo e que tem que atuar como protagonista da sua história com desejo de transformar e fortalecer o desenvolvimento do cenário atual em que a política e a sociedade se encontram.

\section{REFERÊNCIAS}

CHAUÍ, Marilena. Convite à filosofia. São Paulo: Ática, 2010

BRASIL. Ministério da Educação. Secretaria de Educação Média e Tecnológica. Parâmetros Curriculares Nacionais (Ensino Médio). Brasília: MEC, 2000.

BRASIL. Presidência da República. Casa Civil. Subchefia para Assuntos Jurídicos. Lei $\mathrm{n}^{\circ}$ 11.684, de 2 de junho de 2008. Disponível em: $<$ http://portal.mec.gov.br/setec/arquivos/pdf/rceb04 06.pdf> Acesso em: 20 Nov.2019.

BRASIL. Ministério da Educação Conselho Nacional de Educação Câmara da Educação Básica. Resolução $n^{\circ}$ 1, de 15 de maio de 2009. Disponível em: < http://portal.mec.gov.br/dmdocuments/resolucao cne ceb001 2009.pdf>.

Acesso e: 20 de Nov.2019.

CANDAU, Vera Maria et al. Oficinas pedagógicas de direitos humanos. 3 ed. Petrópolis: Vozes, 1999.

GARCIA, Alexandra. Sociologia da Educação: debates clássicos na formação de professores / Rita de Cássia Grecco dos Santos (org.)- Rio Grande: Editora da FURG, 2013. Disponível em: $<$ http://www.sabercom.furg.br/bitstream/1/1585/1/Sociologia-da-educacaodebates -classicos-na-formacao-de-professores.pdf>. Acesso em 23 Nov.2019.

GONH, M.G. Teorias dos Movimentos Sociais - paradigmas clássicos e contemporâneos. São Paulo: Loyola, 1997. 
GUIMARÃES, Elisabeth da Fonseca. Epistemologia e cidadania: o ensino de Sociologia na Educação Básica. In: VIEIRA, José Glebson; CUNHA (Org.). Desafios e perspectivas do ensino e da formação de professores de Sociologia para o Ensino Médio. Mossoró/RN: UERN, 2014.

SILVA, lleizi Luciana Fiorelli. 0 ensino das Ciências Sociais/Sociologia no Brasil: histórico e perspectivas. MORAES, Amaury Cesar. et al. Coleção Explorando o Ensino. - Brasília: Ministério da Educação, Secretaria de Educação Básica, 2010

KOWAN, W. O. Ensino de Filosofia - perspectiva. Belo Horizonte: Autêntica, 2002. 